\title{
Automated method for structural segmentation of nasal airways based on cone beam computed tomography
}

Maksym Yu. Tymkovych, Oleg G. Avrunin, Victor G. Paliy, Maksim Filzow, Oleksandr Gryshkov, et al. 


\title{
Automated method for structural segmentation of nasal airways based on cone beam computed tomography
}

\author{
Maksym Yu. Tymkovych*a, Oleg G. Avrunin ${ }^{\mathrm{a}}$, Victor G. Paliy ${ }^{\mathrm{b}}$, Maksim Filzow ${ }^{\mathrm{c}}$, \\ Oleksandr Gryshkov ${ }^{\mathrm{c}}$, Birgit Glasmacher ${ }^{\mathrm{c}}$, Zbigniew Omiotek $^{\mathrm{d}}$, Róża Dzierżak ${ }^{\mathrm{d}}$, Saule Smailova ${ }^{\mathrm{e}}$, \\ Ainur Kozbekova ${ }^{\mathrm{f}}$ \\ ${ }^{a}$ Kharkiv National University of Radio Electronics, Kharkiv, Ukraine; ${ }^{b}$ National Pirogov Memorial \\ Medical University, Vinnytsya, Ukraine; ${ }^{c}$ Leibniz University, Hannover, Germany; ${ }^{\mathrm{d}}$ Lublin \\ University of Technology, Lublin, Poland; ${ }^{\mathrm{e} D}$. Serikbayev East Kazakhstan State Technical \\ University, Ust-Kamenogorsk, Kazakhstan; Institute of Information and Computational \\ Technologies, Almaty, Kazakhstan
}

\begin{abstract}
The work is dedicated to the segmentation problem of human nasal airways using Cone Beam Computed Tomography. During research, we propose a specialized approach of structured segmentation of nasal airways. That approach use spatial information, symmetrisation of the structures. The proposed stages can be used for construction a virtual three dimensional model of nasal airways and for production full-scale personalized atlases. During research we build the virtual model of nasal airways, which can be used for construction specialized medical atlases and aerodynamics researches.
\end{abstract}

Keywords: analysis, cone beam computed tomography, DICOM, image processing, nasal airways, structural segmentation

\section{INTRODUCTION}

Research of breathing parameters is an important task for understanding of process of nasal aerodynamics ${ }^{1-4}$. One of the most important characteristics which determine the aerodynamics of breathing process is geometry of nasal cavities ${ }^{5-9}$. Main source of data which can represent internal structure of living biological objects in medical practice is CT and $\mathrm{MRI}^{10-13}$. At the same time for researching of nasal airways and paranasal sinuses one of the most precise techniques is cone beam computed tomography, which has many advantages ${ }^{14-16}$. Building of three-dimensional model of investigated structures using manual segmentation is very time-consuming approach. If we take near 400 slices of cone beam computed tomography, user need to make manual segmentation on each of these slices, and also, their must know anatomical structure of that slices. At that it is necessary to develop technique for automated structured segmentation of nasal airways and paranasal sinuses. A solution of that problem must allow determine a three-dimensional structure and parameters (like airflow resistance) of personalized nasal airways. That must allow to do personalized analysis and research of patients from different points of views. The resulted three-dimensional model can be used for virtual visualization of spatial structure, and for full-scale researches (using $3 \mathrm{~d}$ printing technologies) ${ }^{17-19}$.

\section{REVIEW OF THE STATE OF THE ART}

The image segmentation is a wide class of tasks in different fields. Nowadays, many researches worked on the tasks of image segmentation for different applications. One of the most complicated and one of the most important fields is a segmentation of anatomical structures. Initial data are introscopic images of different nature. At the same time, we need to take into account that for different nature of image and for different segmented structures we can use different approaches for segmentation. Some works ${ }^{20-22}$ focus on application multilevel segmentation using Otsu thresholding. One of the most interesting methods of segmentation is the level set approach.

*maksym.tymkovych@nure.ua

Photonics Applications in Astronomy, Communications, Industry, and High Energy Physics Experiments 2017, edited by Ryszard S. Romaniuk, Maciej Linczuk, Proc. of SPIE Vol. 10445, 104453F

(c) 2017 SPIE · CCC code: $0277-786 X / 17 / \$ 18 \cdot$ doi: $10.1117 / 12.2280922$ 
One of the main disadvantages of those methods is a necessary to use the initial contour. For example, another work ${ }^{23}$ is devoted to excluding those problems. One of the most important tasks is the segmentation of nasal airways and nasal sinuses. At the same time we need to evaluate quality of segmentation. Also, some works are devoted to the quality evaluation ${ }^{24}$.

\section{THE PURPOSE AND OBJECTIVES OF THE STUDY}

The automated segmentation of nasal airways and paranasal sinuses are very important task for reconstruction of individualized three-dimensional model of patient. That model can be used for solving the main problem - modeling of a nasal breathing ${ }^{34-35}$. This model should take into account possible results of surgery intervention. Therefore the main task of the work is automation of the segmentation process of nasal airways and paranasal sinuses on the slices of cone beam computed tomography ${ }^{36-39}$. We also need to take into account that it is necessary to make structured segmentation (a need for making analysis of anatomical composition of nasal cavities). At first, we need to make segmentation of meatus nasi inferior, meatus nasi medius, meatus nasi superior, sinus maxillaris, sinus frontalis, sinus sphenoidalis and sinus cellular ethmoidales.

\section{DEVELOPMENT OF THE METHOD OF STRUCTURED SEGMENTATION OF THE NASAL AIRWAYS}

All data presented in DICOM study. The initial data is a set of cone beam computed tomography. A slice was conducted on a Pax-Duo3D by Vatech company. Data was conducted in the standing position (DICOM tag 0018:5100 is equal to "STANDING" value). The scanning region is presented in Fig. 1. The slice thickness (DICOM tag 0018:0050) is equal to $0.20 \mathrm{~mm}$. The measurement parameters: $\mathrm{KVP}=86$ tube current $\mathrm{AI}=6400 \mathrm{~mA}$. The pixel spacing $0.20 \mathrm{~mm} / 0.20$ $\mathrm{mm}$. The width and height of slices are equal to $600 \mathrm{px}$. Fig. 2. shows an example of a slice of a cone beam computed tomography.

a)

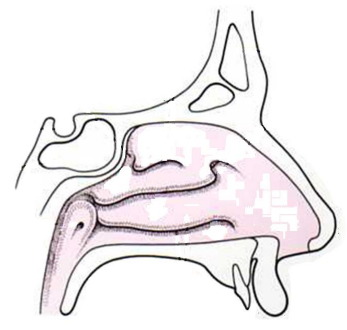

b)

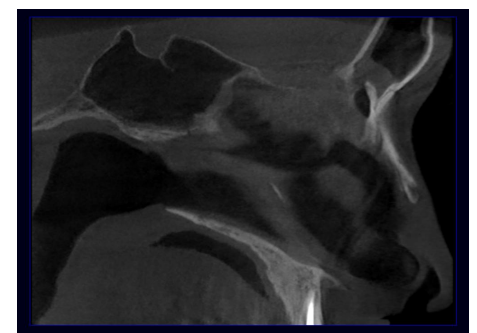

Figure 1. Scanning region example: a) schematically view; b) real sagittal view.

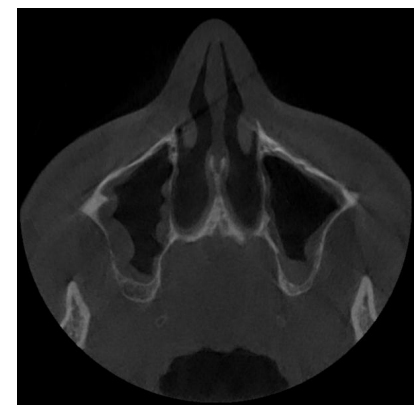

Figure 2. An example of a slice of a cone beam computed tomography. 
For segmentation we propose the following slice processing workflow (Fig. 3.).

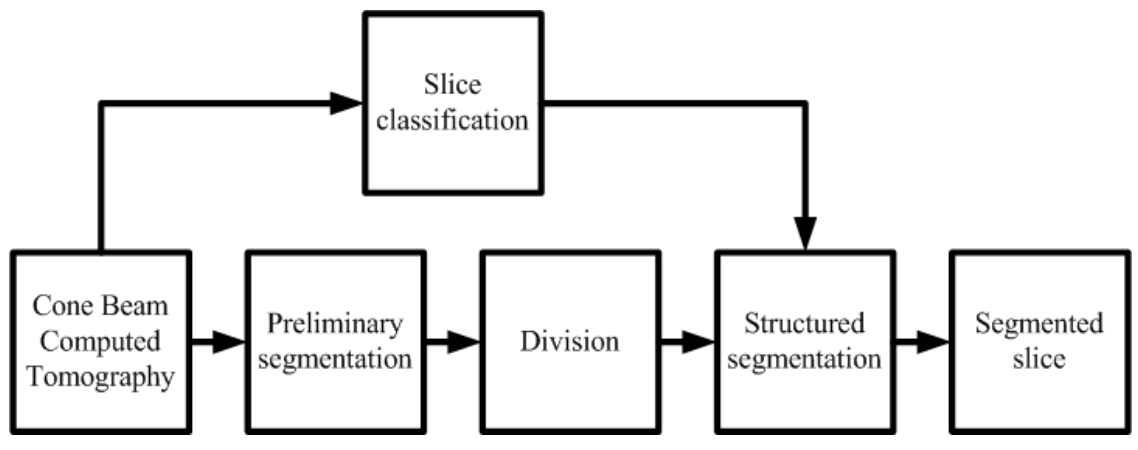

Figure 3. The main stages of the slice processing.

For the determination of a slice position (slice classification) we propose to use an approach presented by Avrunin et al. ${ }^{25}$. Stage of preliminary segmentation must divide slice in two segments: airways and paranasal sinuses, and all the others (Fig. 4.).

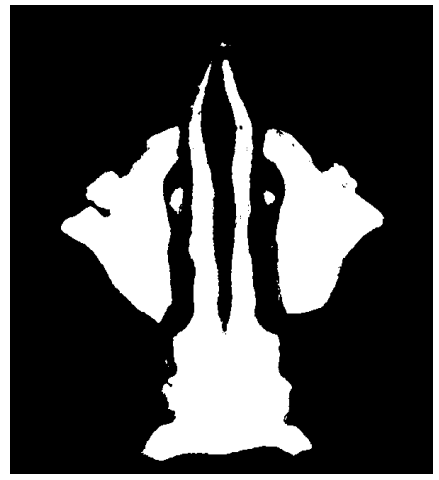

Figure 4. The preliminary segmented slice.

For this purposes we use level thresholding (1). Because our structures (sinuses and airways) contain airway, we can divide that structures from others using scale of Hounsfield:

$$
I_{\text {out }}(x, y)=\left\{\begin{array}{l}
1, \text { if } I_{\text {in }}(x, y)<T \\
0, \text { otherwise }
\end{array}\right.
$$

where $x, y$ are pixel coordinates, $I_{i n}, I_{\text {out }}$ are input and output slices, $T$ is a threshold. To divide segmented image into isolated pixel groups we use morphological erosion operator. This procedure allows to break thin part of images (Fig. 5.).

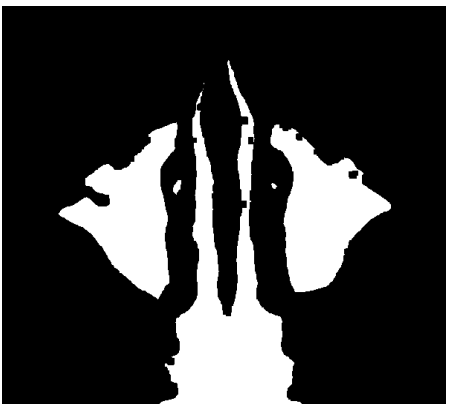

Figure 5. The divided slice. 
Based on the information about the slice class (slice position) for each group of pixels (region of pixel), we can add semantic information about a structure name. For example, we know a spatial position of the anatomical structure on a slice with a special class (Fig. 6.).

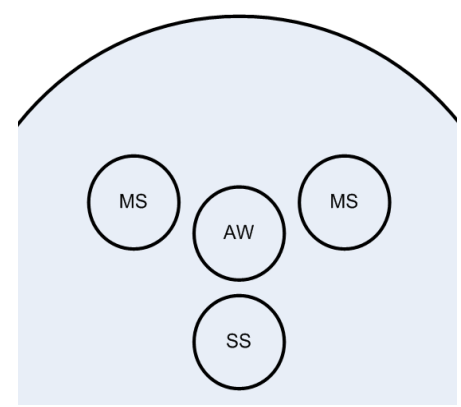

Figure 6. Spatial information for a slice: MS is a maxillary sinus; SS is a sphenoid sinus; AW is an airway.

At this stage, for each pixel group we calculate a centroid of the group:

$$
\left\{\begin{array}{c}
C_{x}=\frac{\sum_{i=1}^{N} x_{i}}{N} ; \\
C_{y}=\frac{\sum_{i=1}^{N} y_{i}}{N},
\end{array}\right.
$$

where $C_{x}, C_{y}$ define a center of a pixel group, $\mathrm{N}$ is a count of pixels in the group, $x_{i}, y_{i}$ are coordinates of the $\mathrm{i}^{\text {th }}$ pixel. For each centroid, we find best (nearest) probably anatomical structure using Euclidian distance:

$$
\text { dist }=\sqrt{\left(G_{x}^{j}-C_{x}\right)^{2}+\left(G_{y}^{j}-C_{y}\right)^{2}},
$$

where $G_{x}, G_{y}$ are coordinates (at the spatial information slice) of some anatomical structure j. At the final stage (Fig. 7.), we have marked groups of pixels (superpixels). We eliminate some groups (based on a slice level information and statistical characteristics of a group). We need to divide some groups using information from other slices.

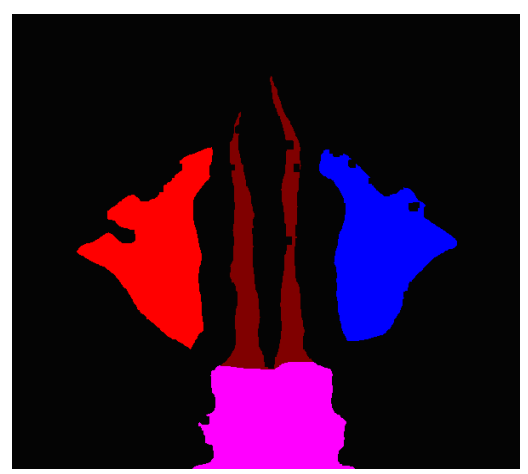

Figure 7. Segmented slice at the final processing stage.

\section{RESULTS AND DISCUSSION}

The developed technique for structured segmentation of nasal structures can segment most of nasal structures. But presented technique has some disadvantages. One of them is a necessary to select threshold $T$ (1) at the stage of preliminary segmentation (Fig. 8.). This value can be varied in many disorders (such as sinusites). 
a)

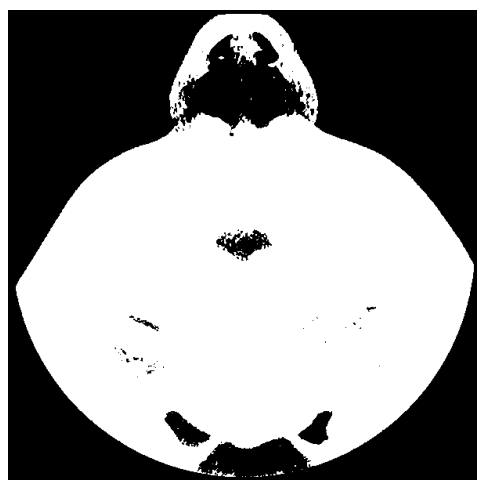

b)

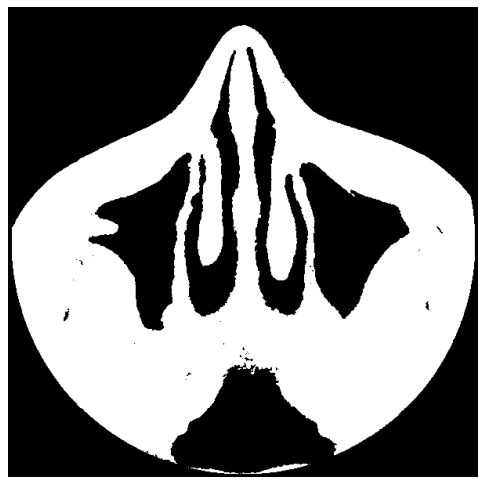

c)

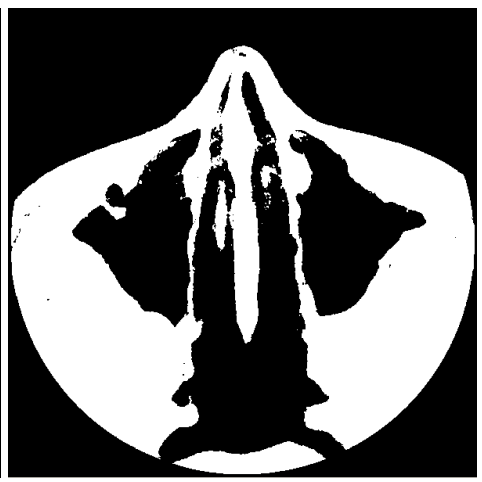

Figure 8. The segmented slices with $\mathrm{T}=500 \mathrm{HU}$ : a) big threshold; b) appropriate threshold; c) small threshold.

As shown in Fig. 8., the constant threshold may give different results for different cases. Very important is also a process of segments division. Depend on the iteration count of a process erosion, we can take different count of segments (Fig. 9.). Some structures can be combined in a one structure. In addition, elimination of small segments (using the feature of area) can lead to losing the small and important parts of aeronasal cavities. That is why we need to work on the improvement of this process.

a)

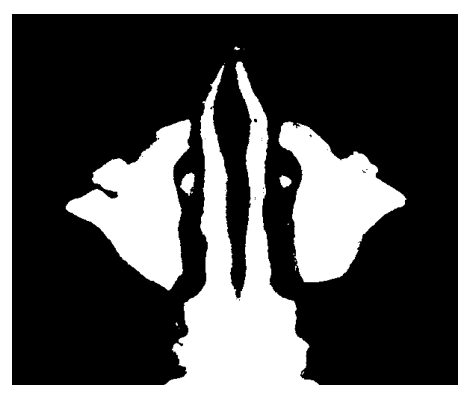

b)

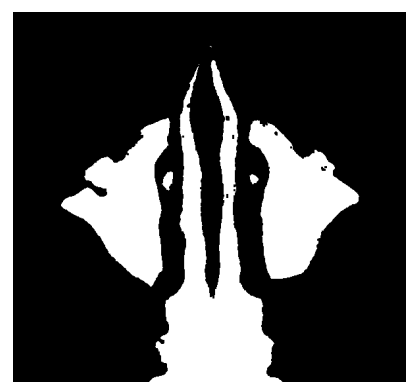

c)

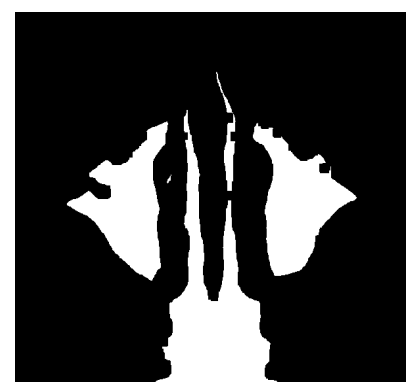

d)

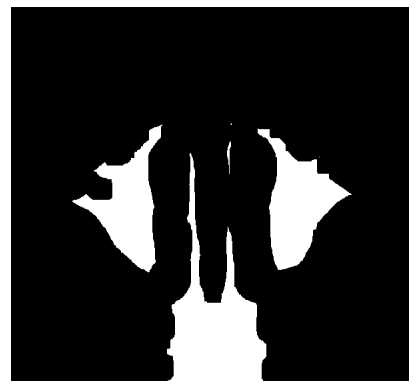

Figure 9. The slice division: a) initial slice; b) one iteration of erosion; c) five iterations of erosion; d) ten iterations of erosion.

\section{CONCLUSIONS}

The study examined the current status of actual problems in the medical image processing ${ }^{26-33}$. The papers show the necessary to develop the specialized technique for structured segmentation of nasal airways. We develop the technique for structured segmentation of nasal airways, which use spatial information of segmented slice. This technique has its advantages and disadvantages. We need to improve that technique for doing segmentation of not standard cases and making more detailed anatomical segmentation. Segmented data can be used for numerical analysis of nasal airways, namely, to calculate their aerial resistance. An important step in the next study is to develop a generalized method of segmentation of the airway. In addition to direct segmentation method, it should isolate features geometry that is segmented. This will be obtained with an additional information which can be used for tasks assessment of a nasal surgery as well as after this process, for modeling of the operational impact and the obtained results. The next stage of this work will be to improve the proposed approach and utilization of that approach for the tasks of numerical and natural functional analysis of nasal airways. That will improve the quality of functional diagnosis of the breathing. 


\section{REFERENCES}

[1] Al-Omari, A. K., Saied, H. F. I. and Avrunin, O. G., "Analysis of Changes of the Hydraulic Diameter and Determination of the Air Flow Modes in the Nasal Cavity," Image Processing \& Communications Challenges 2 AISC 102, 303-310 (2011).

[2] Knigavko, Y., Avrunin, O. and Farouk, H., "Calculation of functional parameters to determine the indications for rhinoplasty," Eastern-European Journal of Enterprise Technologies, Applied information technology 2/10(62), 24-27 (2013).

[3] Saied, H. F. I., Al-Omari, A. K. and Avrunin, O. G., "An Attempt of the Determination of Aerodynamic Characteristics of Nasal Airways," Image Processing \& Communications Challenges 2, AISC 102, 311-322 (2011).

[4] Nosova, Y., Shushliapina, N., Kostishyn, S. V., Koval, L. G., Omiotek, Z., Wójcik, W. and Tuleshova, A., "The use of statistical characteristics of measured signals to increasing the reliability of the rhinomanometric diagnosis," Proc. SPIE 10031, (2016).

[5] Paiva, J. B., Freire-Maia, B. A. V., Neto, J. R., Francesco, R. C. and Voegels, R. L., "Evaluation of children nasal geometry, employing accoustic rhinometry," Brazilian Journal of Otorhinolaryngology 76(3), 355-362 (2010).

[6] Gomes, A. O. C., Sampaio-Teixeira, A. C. M., Trindade, S. H. K. and Trindade, I. E. K., "Nasal cavity geometry of healthy adults assessed using acoustic rhinometry," Brazilian Journal of Othorinolaryngology 74(5), 746-754 (2008).

[7] Javaheri, E., Golshahi, L. and Finlay, W. H., "An idealized geometry that mimics average infant nasal airway deposition," Journal of Aerosol Science 55, 137-148 (2013).

[8] White, D. E., Bartley, J., Shakeel, M., Nates, R. J. and Hankin, R. K. S., "Nasal airway responses to nasal continuous positive airway pressure breathing: An in-vivo pilot study," Journal of Biomechanics 49(9), 18871890 (2016).

[9] Schneider, D., Kammerer, P. W., Schon, G., Bschorer, R., "A three-dimensional comparison of the pharyngeal airway after mandibular distraction osteogenesis and bilateral sagittal split osteotomy," Journal of CranioMaxillo-Facial Surgery 43(8), 1632-1637 (2015).

[10] Kettani, N. E.-C., Benabdeljlil, M., Bellakhdar, F., Fikri, M., Hassani, M. R., Alaoui-Faris, M. and Jiddane, M., "Technique de repérage IRM/TDM des noyaux sous-thalamiques pour leur stimulation dans le cadre du traitement de la maladie de Parkinson," Feuillets de radiologie 56(2), 101-104 (2015).

[11] Matsumoto, M. M. S., Udupa, J. K., Tong, Y., Saboury, B. and Torigian, D. A., "Quantitative Normal Thoracic Anatomy at CT," Computerized Medical Imaging and Graphics 51, 1-10 (2016).

[12] Rinuncini, M., Zuin, M., Scoranello, F., Fejzo, M., Rampin, L., Rubello, D., Faggian, G. and Roncon, L., "Differentiation of cardiac thrombus from cardiac tumor combining cardiac MRI and 18F-FDG-PET/CT Imaging," International Journal of Cardiology 212, 94-96 (2016).

[13] Ohno, Y., Yoshikawa, T., Takenaka, D., Fujisawa, Y., Sugihara, N., Kishida, Y., Seki, S., Koyama, H., Sugimura, K., "Xenon-enhanced CT using subtraction CT: Basic and preliminary clinical studies for comparison of its efficacy with that of dual-energy CT and ventilation SPECT/CT to assess regional ventilation and pulmonary functional loss in smokers(2016)," European Journal of Radiology 86, 41-51 (2017).

[14] Casselman, J. W., Gieraerts, K., Volders, D., Delanote, J., Mermuys, K., De Foer, B. and Swennen, G., "Cone Beam CT: Non-Dental Applications," Journal of the Belgian Society of Radiology 96(6) , 333-353 (2013).

[15] Parks, E., "Cone Beam Computed Tomography for the Nasal Cavity and Paranasal Sinuses," Dental Clinics of North America 58(3), 627-651 (2014).

[16] Choi, J.-W., Lee, S.-S., Choi, S.-C., Heo, M.-S., Huh, K.-H., Yi, W.-J., Kang, S.-R., Han, D.-H. and Kim, E.-K., "Relationship between physical factors and subjective image quality of cone-beam computed tomography images according to diagnostic task," Oral Surgery, Oral Medicine, Oral Pathology and Oral Radiology 119(3), 357-365 (2015).

[17] Itagaki, M. W., "Using 3D printed models for planning and guidance during endovascular intervention: a technical advance, Diagnostic and Interventional Radiology," 21(4), 338-341 (2015). 
[18] Moraes, P. H., Olate, S., Cantin, M., Assis, A. F., Santos, E., Silva, F.O. and Silva, L. O., "Anatomical Reproducibility through 3D Printing in Cranio-Maxillo-Facial Defects," International Journal of Morphology, 33(3), 826-830 (2015).

[19] Pietrabissa, A., Marconi, S., Peri, A., Pugliese, L., Cavazzi, E., Vinci, A., Botti, M. and Auricchio, F., "From CT scanning to 3-D printing technology for the preoperative planning in laparoscopic splenectomy," Surgical Endoscopy 30(1), 366-371 (2016).

[20]Zhang, X., Zhao, H., Li, X., Feng, Y. and Li, H., "A multi-scale 3D Otsu thresholding algorithm for medical image segmentation," Digit. Signal Process., (2016).

[21] Bhandari, A. K., Kumar, A. and Singh, G. K., "Modified Artificial Bee Colony based Computationally Efficient Multilevel Thresholding for Satellite Image Segmentation using Kapur's, Otsu and Tsallis Functions," Expert Systems with Applications 42(3), 1573-1601 (2015).

[22]Raja, N. S. M., Sukanya, S. A. and Nikita, Y., "Improved PSO based Multi-Level Thresholding for Cancer Infected Breast Thermal Images using Otsu," Procedia Computer Science 48, 524-529 (2015).

[23] Liu, Q., Jiang, M., Bai, P. and Yang, G., "A novel level set model with automated initialization and controlling parameters for medical image segmentation," Computerized Medical Imaging and Graphics 48, 21-29 (2016).

[24] Alsufyani, N. A., et al., "New algorithm for semiautomatic segmentation of nasal cavity and pharyngeal airway in comparison with manual segmentation using cone-beam computed tomography," American Journal of Orthodontics and Dentofacial Orthopedics 150(4), 703-712 (2016).

[25] Avrunin, O. G., Tymkovych, M. Y., Pavlov, S. V., Timchik, S. V., Kisała, P. and Orakbaev, Y., "Classification of CT-brain slices based on local histograms," Proc. SPIE 9816, (2015).

[26]Zabolotna, N. I., Wojcik, W., Pavlov, S. V., Ushenko, O. G. and Suleimenov, B., "Diagnostics of pathologically changed birefringent networks by means of phase Mueller matrix tomography," Proc. SPIE 8698, (2012).

[27] Rovira, R., Bayas, M. M., Pavlov, S. V., Kisała, P. and Yussupova, G., "Application of a modified evolutionary algorithm for the optimization of data acquisition to improve the accuracy of a video-polarimetric system," Proc. SPIE 9816, (2015).

[28]Zabolotna, N. I., Pavlov, S. V., Ushenko, A. G., Sobko, O. V. and Savich, V. O., "Multivariate system of polarization tomography of biological crystals birefringence networks," Proc. SPIE 9166, (2014).

[29] Chepurna, O., Shton, I., Kholin, V., Voytsehovich, V., Popov, V., Pavlov, S., Gamaleia, N., Wójcik, W. and Zhassandykyzy, M., "Photodynamic therapy with laser scanning mode of tumor irradiation," Proc. SPIE 9816, (2015).

[30] Rovira, R. H, Pavlov, S. V, Kaminski, O. S. and Bayas, M. M., "Methods of Processing Video Polarimetry Information Based on Least-Squares and Fourier Analysis," Middle-East Journal of Scientific Research, (2013).

[31] Pavlov, S. V., Vassilenko, V. B., Vovkotrub, D. V., Poplavskaya, A. A. and Hotra, O., "Methods of processing biomedical image of retinal macular region of the eye," Proc. SPIE 8698, (2012).

[32] Romanyuk, O. N., Pavlov, S. V., Melnyk, O. V., Romanyuk, S. O., Smolarz, A., et al., "Method of anti-aliasing with the use of the new pixel model," Proc. SPIE 9816, (2015).

[33] Romanyuk, O. N., Pavlov, S. V., Dovhaliuk, R. Yu., Babyuk, N. P., Obidnyk, M. D., et al., "Microfacet distribution function for physically based bidirectional reflectance distribution functions," Proc. SPIE 8698, (2012).

[34]Zlepko, S. M., Tymchyk, S. V., Novikova, A. O., Moskovko, M. V., Zlepko, A. S., Omiotek, Z., MałeckaMassalska, T., "An informational model of sportsman's competitive activities," Proc. SPIE 10031, (2016).

[35] Rovira, R. H., Tuzhanskyy, S. Ye, Pavlov, S. V., et al., "Polarimetric characterisation of histological section of skin with pathological changes," Proc. SPIE 10031, (2016).

[36] Wójcik, W., Golec, T., Kotyra, A., Smolarz, A., Komada, P., Kalita, M., "Concept of application of signals from fiber-optic system for flame monitoring to control separate pulverized coal burner," Proc. SPIE 5484, 427431 (2004).

[37] Komada, P., Cieszczyk, S., "Application of Multiple Line Integrated Spectroscopy on CO Concentration Measurement," Elektronika Ir Elektrotechnika 19(9), 46-49 (2013).

[38] Lawicki, T., "Odszumianie obrazów CT za pomocą transformaty curvelet," Przegląd Elektrotechniczny 2(91), 222-224 (2015). 
[39] Prokop, P., "Zastosowanie metody Chan-Vese w segmentacji obrazów medycznych," Informatyka, Automatyka, Pomiary w Gospodarce i Ochronie Środowiska 4, 32-37 (2015). 